\title{
Role of Glutathione S-Transferase (GSTM1 and GSTT1) Genes Deletion in Susceptibility to HIV-1 Disease Progression
}

\author{
Florencia Wendkuuni Djigma ${ }^{1,2 * \#, ~ P e g d w e n d e ́ ~ A b e l ~ S o r g h o ~}{ }^{1,2 \#, ~}$ \\ Serge Théophile Soubeiga ${ }^{1,2,3}$, Albert Théophane Yonli1,2, Herman Karim Sombie ${ }^{1,2}$, \\ Isabelle Touwendpoulimdé Kiendrebeogo ${ }^{1,2}$, Tégwindé Rebeca Compaore ${ }^{1,2,3}$, \\ Abdoul Karim Ouattara1,2, Bapio Valérie Jéan Télesphore Elvira Bazie1,2, \\ Bolni Marius Nagalo',2,4, Jacques Simpore ${ }^{1,2}$
}

${ }^{1}$ Molecular Biology and Genetics Laboratory (LABIOGENE), Department of Biochemistry and Microbiology, University JOSEPH KI-ZERBO, Ouagadougou, Burkina Faso

${ }^{2}$ Pietro Annigoni Biomolecular Research Center (CERBA), Ouagadougou, Burkina Faso ${ }^{3}$ Institut de Recherche en Sciences de la Sante (IRSS), Biomedical and Public health Department, Ouagadougou, Burkina Faso ${ }^{4}$ Division of Hematology and Oncology, Mayo Clinic, Scottsdale, AZ, USA

Email: ^florencia.djigma@gmail.com, ${ }^{\star}$ f.djigma@labiogene.org

How to cite this paper: Djigma, F.W., Sorgho, P.A., Soubeiga, S.T., Yonli, A.T., Sombie, H.K., Kiendrebeogo, I.T., Compaore, T.R., Ouattara, A.K., Bazie, B.V.J.T.E., Nagalo, B.M. and Simpore, J. (2020) Role of Glutathione S-Transferase (GSTM1 and GSTT1) Genes Deletion in Susceptibility to HIV-1 Disease Progression. Journal of Biosciences and Medicines, 8, 41-54.

https://doi.org/10.4236/jbm.2020.82004

Received: December 30, 2019

Accepted: February 1, 2020

Published: February 4, 2020

Copyright $\odot 2020$ by author(s) and Scientific Research Publishing Inc. This work is licensed under the Creative Commons Attribution International License (CC BY 4.0).

http://creativecommons.org/licenses/by/4.0/ (c) (i) Open Access

\begin{abstract}
Background: Glutathione S-transferases (GSTs) are multifunctional enzymes which play an important role in oxidative stress pathways by conjugation with glutathione. Oxidative stress is one of several risk factors that may be associated with many types of diseases progression such as cancer and infectious diseases. In this study, we investigated the association between the polymorphism of GSTM1 and GSTT1 genes and the risk of HIV-1 disease progression. Methods: We conducted a case-control study including 313 participants of Burkina Faso: 153 HIV-1 infected individuals on antiretroviral treatment (ART) and $160 \mathrm{HIV}-1$ negative individuals as controls. Presence or absence of the GSTM1 and GSTT1 genes was determined using multiplex polymerase chain reaction (PCR). $\mathrm{CD} 4^{+} \mathrm{T}$ counts and HIV-1 viral load were measured in patients using respectively BD FACSCount and Abbott m2000rt instruments. Results: Frequencies of GSTM1-null and GSTT1-null were 30.35\% and 35.46\% respectively and the frequency of double deletion GSTM1-null/GSTT1-null was 14.38\% in the general study population. GSTM1-null $(30.35 \%$ versus $69.65 \%$; OR $=$ $1.90 ; \mathrm{p}=0.010)$, GSTT1-null $(35.46 \%$ versus $64.54 \% ; \mathrm{OR}=3.11 ; \mathrm{p}<0.001)$, GSTM1-active/ GSTT1-null (21.08\% versus 48.56\%; OR = 3.17; $\mathrm{p}<0.001)$ and the double deletion GSTM1-null/GSTT1-null (14.38\% versus $48.56 \%$; OR = 4.46; $\mathrm{p}<0.001)$ were more present in cases group than controls and differences
\end{abstract}


were significant. GSTM1-null and GSTM1-null/GSTT1-null were associated with increased odds of low $\mathrm{CD} 4^{+}$count $\left(<350 \mathrm{cells} / \mathrm{mm}^{3}\right)$ and high HIV-1 viral load ( $\geq 1000$ copies $/ \mathrm{mL}$ ). Conclusion: GSTM1-null, GSTT1-null genotype, the double genotypes GSTM1-active/GSTT1-null and GSTM1-null/GSTT1-null were associated with HIV-1 disease progression and GSTM1-null and GSTM1null/GSTT1-null genotypes were associated with low $\mathrm{CD}^{+} \mathrm{T}$ cells counts and high HIV-1 viral load in HIV-linfected patients on ART.

\section{Keywords}

HIV-1, GSTM1, GSTT1, Burkina Faso

\section{Introduction}

Human immunodeficiency virus (HIV) and AIDS remain persistent public health concerns in Sub-Saharan Africa. In 2018, the World health organization reported that more about 35 million patients had died due to HIV infection, making it one of the most serious life-threatening human diseases in both 20th and 21st century [1]. Sub-Saharan Africa is one of the most affected regions by HIV infection globally, with an estimated 25.6 million people living with the disease [1]. In 2016, in Burkina Faso 3400 new cases of HIV infection and approximately 95,000 people who are living with HIV were reported [2]. As HIV progresses, host immunity is depleted from its most effective immune cells (CD4 ${ }^{+} \mathrm{T}$ cells), thus increasing body's vulnerability to opportunistic infections. Antiretroviral treatment is therefore needed to prevent viral multiplication and correct CD4 $\mathrm{T}$ cell levels.

Several studies have reported high rate of therapeutic failures [3] [4] [5] and investigations have been conducted to develop more effective therapies to inhibit HIV replication in infected patients. Moreover, studies on host/pathogen interactions have contributed to improve our knowledge on HIV molecular pathogenicity in human. Currently, investigations have focused on understanding host-genetic factors that could potentially modulate cellular susceptibility to HIV replication [6] [7].

Glutathione S-transferase (GSTs) are a super family of drug metabolizing enzymes with a high level of conjugation specificity for glutathione (GSH) and the enzymes are essential for metabolism of many substances, responsible for response to oxidative stress in humans. There are eight groups of enzyme namely alpha (GSTA), mu (GSTM), theta (GSTT), pi (GSTP), sigma (GSTS), kappa (GSTK), omega (GSTO) and zeta (GSTZ) which are involved in the detoxification of compounds in drugs and carcinogens, and for inhibition of oxidative damage to tissues [8]. The Glutathione S-transferases GSTM1 and GSTT1 are highly polymorphic genes belonging, respectively to the $m u$ and theta classes [9] [10], and they are the most studied. Polymorphisms in GST are associated to higher risk of oxidative stress, which has been suggested to promote HIV replication [11] [12]. There are two types of polymorphisms in glutathione S-Transferase genes: the 
homozygous deletion genotype (null genotype) which has been associated with loss of enzymatic activity and one or two undeleted genotype (called non-null or present genotype). GSTM1 and GSTT1 are located respectively on chromosome 1 p13.3 and 22q11.23 and the enzymes are involved in the conjugation and detoxification of some drug containing butadiene epoxide, bromodichloromethane, dichloromethane, ethylene dibromide, methylene chloride and ethylene oxide [13] [14] [15]. The GSTM1-null and GSTT1-null genotypes are deletion variants associated with the lack of a group of enzymes associated to the susceptibility of developing certain diseases, such as infectious diseases, cancers and others, possibly due to an amplified susceptibility to the harmful effects of oxidative stress, environmental toxins and carcinogens [15]-[20]. Studies on GSTM1 and GSTT1 genotypes have been associated to the risk of HIV-1 disease progression, but rather the results are still controversial. This study was designed to investigate the association between the polymorphisms of GSTM1 and GSTT1 genes and the risk of HIV-1 disease progression in Burkina Faso.

\section{Material and Methods}

\subsection{Ethical Consideration}

This study protocol was approved by CERBA/LABIOGENE Ethics Committee. All participants have given written and informed consent according to the Helsinki's Declarations.

\subsection{Type and Population of Study}

This is a case-control study which was conducted from December 2018 to June 2019. A total of 313 individuals were included in this investigation, which consisted of $153 \mathrm{HIV}-1$ infected patients on antiretroviral treatment (ART) and 160 HIV-1 negative individuals as controls. All subjects were seronegative for hepatitis $\mathrm{B}(\mathrm{HBV})$ and $\mathrm{C}(\mathrm{HCV})$ infections.

\subsection{Samples Collection and Research for HIV, HBV and HCV Viral Markers}

After giving their informed consent, approximately $10 \mathrm{~mL}$ of venous blood of HIV-1 infected patients and healthy voluntary non-remunerated blood donors was collected in dry and EDTA tubes. Serological tests using four-generation ELISA Ag/Ab were performed for HIV, HBV and HCV screening and confirmation in the control group, using cobas e 411 Analyzer (Roche Diagnostics GmbH Mannheim Germany) according to the manufacturer's protocol.

\subsection{Determination of Lymphocyte CD4+ Count and HIV-1 Viral Load}

Becton Dickson FACSCount machine (Becton, Dickson and company, San Jose, $\mathrm{CA}$ ) was used to determine $\mathrm{CD} 4^{+} \mathrm{T}$ cells counts following the manufacturer's protocol.

Viral RNA was extracted from $200 \mu \mathrm{L}$ of plasma using the "Abbott HIV-1 
m-sample system preparation Kit (Promega, USA)" according to the manufacturer's protocol. HIV-1 viral load was determined using the "Abbott HIV-1 Real Time kit (Promega, USA)" on the Abbott m2000rt system (Abbott Laboratories, Illinois, USA) according to the manufacturer's protocol.

\subsection{Genomic DNA Extraction and Genotyping of GSTM1/GSTT1}

Whole blood was used for genomic DNA extraction using the salting-out method as previously described [21]. DNA purity and concentration were determined using a Biodrop (Isogen Life Science, NV/S.A, Temse, Belgium). GSTM1 and GSTT1 Genotyping was performed according to the method described by Chen et al., (1997) [22]. Briefly we performed multiplex PCR with the GeneAmp PCR system 9700 (Applied Biosystem, USA) in a reaction volume of $25 \mu \mathrm{L}$ including $10 \mu \mathrm{L}$ of Master Mix Ampli Taq Gold ${ }^{\oplus}$ (Appleid Biosystems, USA), $1 \mu \mathrm{L}$ of each of the primer pairs of each gene (Table 1), $7 \mu \mathrm{L}$ of nuclease-free water and $2 \mu \mathrm{L}$ of DNA. The amplification program was as follows: $94^{\circ} \mathrm{C}$ for $5 \mathrm{~min}$ for initial denaturation; 40 cycles of a series of denaturation at $94^{\circ} \mathrm{C}$ for $1 \mathrm{~min}$, hybridization at $57^{\circ} \mathrm{C}$ for $1 \mathrm{~min}$, elongation at $72^{\circ} \mathrm{C}$ for $1 \mathrm{~min}$; and a final extension at $72^{\circ} \mathrm{C}$ for $7 \mathrm{~min}$. PCR products migrated on a $3 \%$ agarose gel migration during 45 min and visualized under UV light at $312 \mathrm{~nm}$ using the Geneflash revelation device. PCR amplification was considered valid if the sample had a band corresponding to $\beta$-globine gene (Figure 1).

Table 1. Sequence of primers for multiplex PCR.

\begin{tabular}{ccc}
\hline Genes & Sequences & Amplicon length (bp) \\
\hline \multirow{2}{*}{ GSTM1 } & 5'-GAACTCCCTGAAAAGCTAAAGC-3' & 215 \\
& 5'-GTTGGGCTCAAATATACGGTGG-3' & \\
GSTT1 & 5'-TTCCTTACTGGTCCTCACATCTC-3' & \multirow{2}{*}{480} \\
& 5'-TCACCGGATCATGGCCAGCA-3' & \\
\multirow{3}{*}{-globin } & 5'-CAACTTCATCCACGTTCACC-3' & 268 \\
& 5'-GAAGAGCCAAGGACAGGTAC-3' & \\
\hline
\end{tabular}

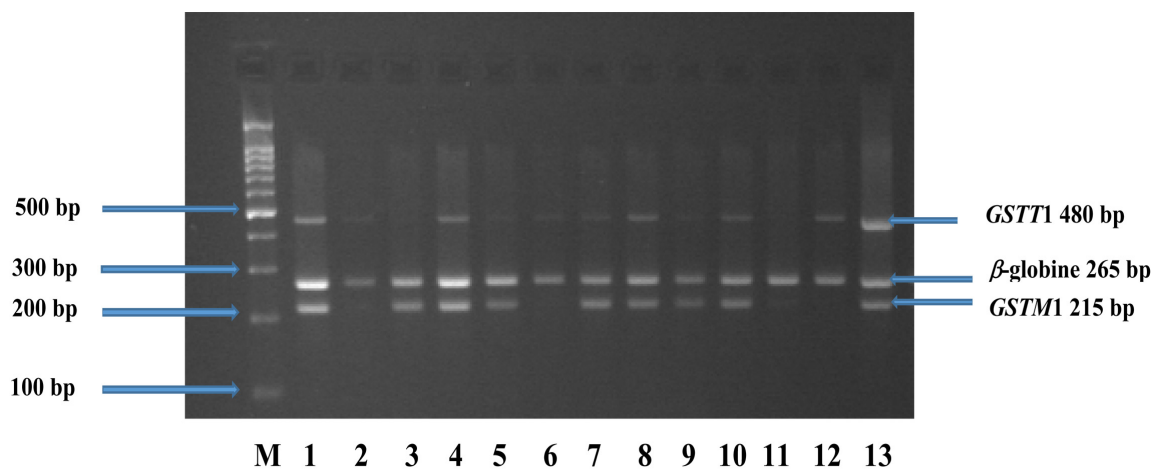

Figure 1. Electrophoresis agarose 3\% gel of DNA fragment of GSTM1 and GSTT1 genes. $\mathrm{M}=$ Molecular weight ladder (100 bp); 1, 4, 5, 7, 8, 9, 10, 13 = Double present genotypes of GSTM1 and GSTT1; 3 = Genotypes of GSTM1 present and GSTT1 null; $11=$ Double genotypes null of GSTM1 and GSTT1; 2, 6, $12=$ GSTM1 null and GSTT1 present. 


\section{Statistical Analysis}

The data was analyzed with the standard Statistical Package for Social Sciences (SPSS) software version 20.0 and Epi-info version 7.1 software (CDC, Atlanta, USA). Association between polymorphisms and HIV-1 infection were established by comparing frequencies between cases and controls using the chi-square test. Relative risk was estimated with Odds Ratio (OR) and 95\% of confidence interval $(95 \%$ CI). p-values < 0.05 or Odds Ratio with a 95\% CI were considered statistically significant.

\section{Results}

The distributions of sociodemographic characteristics are shown in Table 2. In the general study population females were more represented than males $(76.70 \%$ versus $23.30 \%$ ) and were more infected by HIV-1 than males in case group (66.7\% versus $33.3 \%)$. In overall, the individuals aged $\geq 40$ years was the most represented with $55.90 \%$, characterized by 9.82 -fold increased risk to be infected with HIV -1 than individuals aged $\leq 39$ years $(\mathrm{OR}=9.82,95 \% \mathrm{CI}=5.78-16.66$, $\mathrm{p}<0.001)$.

The lymphocytes $\mathrm{CD}^{+}$cells counts were stratified according to the Centers for Diseases Control and Prevention criteria [23]. Among HIV-1 infected patients, $7.84 \%$ and $81.04 \%$ had respectively T CD4+ counts $<200$ cells $/ \mathrm{mm}^{3}$ and $\geq$ 350 cells $/ \mathrm{mm}^{3}$. Also we found that $92.2 \%$ of HIV-1 infected patients had viral load $\leq 1000$ copies $/ \mathrm{mL}$ and patients who had $\mathrm{CD}^{+} \geq 350$ cells $/ \mathrm{mm}^{3}$ and viral load $<1000$ copies/mL were $81.04 \%$.

The distribution of GSTM1 and GSTT1 polymorphism in the study population are shown in Table 3. In the general study population, we found that the frequencies of $G S T M 1$-active and GSTT1-active were $69.65 \%$ and $64.54 \%$ respectively; those of GSTM1-null and GSTT1-null were $30.35 \%$ and $35.46 \%$ respectively.

Table 2. Sociodemographic characteristic of the study population.

\begin{tabular}{|c|c|c|c|c|c|c|}
\hline Variables & $\mathrm{HIV}+n(\%)$ & Controls $n(\%)$ & Total $n(\%)$ & OR & $95 \% \mathrm{CI}$ & p-value \\
\hline \multicolumn{7}{|l|}{ Gender } \\
\hline Male & $51(33.30)$ & $22(13.70)$ & $73(23.30)$ & & & \\
\hline Female & $102(66.70)$ & $138(86.30)$ & $240(76.70)$ & 0.31 & $0.18-0.55$ & $<0.001^{*}$ \\
\hline \multicolumn{7}{|l|}{ Age (years) } \\
\hline$\leq 39$ & $28(18.30)$ & $110(68.70)$ & $138(44.10)$ & & & \\
\hline$\geq 40$ & $125(81.70)$ & $50(31.30)$ & $175(55.90)$ & 9.82 & $5.78-16.66$ & $<0.001^{*}$ \\
\hline \multicolumn{7}{|l|}{ Serological status } \\
\hline HIV+ & $153(100.00)$ & $0(0.00)$ & $153(100.00)$ & - & - & - \\
\hline HIV- & $0(0.00)$ & $160(100.00)$ & $160(100.00)$ & - & - & - \\
\hline $\mathrm{HBV}-/ \mathrm{HCV}-$ & $153(100.00)$ & $160(100.00)$ & $313(100.00)$ & - & - & - \\
\hline
\end{tabular}

Analysis by chi-square to obtain odds ratio values (OR) and confidence interval; HIV+: patients group with HIV-1 infection, HIV-/HBV-/HVC-: controls group without HIV-1; HBV and HCV infection CI: confidence interval; OR: odds ratio; ${ }^{*}$ : reference; ${ }^{*}$ : significant difference between groups $(\mathrm{p}<0.05)$. 
Table 3. Frequencies of GSTM1 and GSTT1 in the general study population.

\begin{tabular}{ccccccc}
\hline Variables & HIV+ $n(\%)$ & Controls $n(\%)$ & Total $n(\%)$ & OR & $95 \%$ CI & p-value \\
\hline${ }^{*}$ GSTM1(+) & $96(62.75)$ & $122(76.25)$ & $218(69.65)$ & 1.00 & & \\
GSTM1(-) & $57(37.25)$ & $38(23.75)$ & $95(30.35)$ & 1.90 & $1.16-3.11$ & $0.010^{*}$ \\
${ }^{*}$ GSTT1(+) & $79(51.63)$ & $123(76.90)$ & $202(64.54)$ & 1.00 & & \\
GSTT1(-) & $74(48.37)$ & $37(23.10)$ & $111(35.46)$ & 3.11 & $1.91-5.05$ & $<0.001^{*}$ \\
${ }^{*}$ GSTM1(+)/GSTT1(+) & $54(35.29)$ & $98(61.25)$ & $152(48.56)$ & 1.00 & & \\
GSTM1(-)/GSTT1(+) & $25(16.34)$ & $25(15.62)$ & $50(15.97)$ & 1.81 & $0.95-3.46$ & 0.094 \\
GSTM1(+)/GSTT1(-) & $42(27.45)$ & $24(15.00)$ & $66(21.08)$ & 3.17 & $1.74-5.79$ & $<0.001^{*}$ \\
GSTM1(-)/GSTT1(-) & $32(20.91)$ & $13(8.13)$ & $45(14.38)$ & 4.46 & $2.16-9.22$ & $<0.001^{*}$ \\
\hline
\end{tabular}

Analysis by chi-square to obtain odds ratio values (OR) and confidence interval; + : active; - : null; $\mathrm{CI}$ : confidence interval; OR: odds ratio; *: reference; ${ }^{*}$ : significant difference between groups $(p<0.05)$.

When we compared frequencies between cases and controls, we found that subjects with GSTM1-null and GSTT1-null genotype were more present in the case group than controls and difference between the two group was significant respectively $(37.25 \%$ versus $23.75 \%$ for $G S T M 1$-null, $\mathrm{OR}=1.90,95 \% \mathrm{CI}=1.16$ $3.11, \mathrm{p}=0.010$ and $48.37 \%$ versus $23.10 \%$ for $G S T T 1$-null $\mathrm{OR}=3.11,95 \% \mathrm{CI}=$ $1.91-5.05, \mathrm{p}<0.001)$. We found significant difference between cases and controls concerning the double genotype GSTM1-active/ GSTT1-null (27.45\% versus $15.00 \%, \mathrm{OR}=3.17,95 \% \mathrm{CI}=1.74-5.79, \mathrm{p}<0.001)$ and the double deletion GSTM1-null/GSTT1-null (20.91\% versus $8.13 \%$; OR $=4.46 ; 95 \% \mathrm{CI}=2.16$ $9.22, \mathrm{p}<0.001)$. But we didn't find any significant difference between cases and controls concerning the double genotype GSTM1-null/GSTT1-active (16.34\% versus $15.62 \%$; $\mathrm{OR}=1.81 ; 95 \% \mathrm{CI}=0.95-3.46, \mathrm{p}=0.094)$.

Table 4 shown the impact of the polymorphisms of GSTM1 and GSTT1 genes in HIV-1 infected patients according to the $\mathrm{CD} 4^{+} \mathrm{T}$ cells counts. $\mathrm{CD} 4^{+} \mathrm{T}$ cells counts was stratified according to the Centers for Diseases Control and Prevention criteria [23]. HIV-1 infected patients with the GSTM1-null were 57 and 41 of them had CD4 $4^{+}$counts $\geq 350$ cells $/ \mathrm{mm}^{3}, 9$ of them had $\mathrm{CD} 4^{+}$count between 200 and 349 cells $/ \mathrm{mm}^{3}$ and 7 had CD4 $4^{+}$count $<200$ cells $/ \mathrm{mm}^{3}$. A total of $74 \mathrm{HIV}-1$ infected patients had GSTT1-null and among them 56 had CD4 $4^{+}$counts $\geq 350$ cells $/ \mathrm{mm}^{3}, 9$ had CD4 $4^{+}$count between 200 and 349 cells $/ \mathrm{mm}^{3}$ and 9 had CD4 ${ }^{+}$ count below 200 cells $/ \mathrm{mm}^{3}$. HIV-1 infected patients with the double genotype GSTM1-null/GSTT1-null were 32 and among them 22 had CD4 $4^{+}$count $\geq 350$ cells $/ \mathrm{mm}^{3}, 5$ had CD4 $4^{+}$count between 200 and 349 cells $/ \mathrm{mm}^{3}$ and 5 too equally had $\mathrm{CD} 4^{+}$below 200 cells $/ \mathrm{mm}^{3}$. A statistically significant difference was found when we compared GSTM1 and GSTT1 variants frequencies in patients with $\mathrm{CD} 4^{+}$ counts $\geq 350$ cells $/ \mathrm{mm}^{3}$ and those with $350<$ cells $/ \mathrm{mm}^{3}$. GSTM1-null genotype and the double genotype GSTM1-null/GSTT1-null variants were less frequent in patients with $\mathrm{CD}^{+}$counts $<350$ cells $/ \mathrm{mm}^{3}$, suggesting that GSTM1-null genotype $(\mathrm{OR}=2.49,95 \% \mathrm{CI}=1.095-5.66, \mathrm{p}=0.033)$ and the double genotype GSTM1-null/GSTT1-null ( $\mathrm{OR}=4.45,95 \% \mathrm{CI}=1.36-14.57, \mathrm{p}=0.016)$ were associated with an higher risk to have $\mathrm{CD} 4^{+}$count less than 350 cells $/ \mathrm{mm}^{3}$. 
Table 4. Impact of GSTM1/GSTT1 deletion on T CD4 count in HIV-1 patients.

\begin{tabular}{|c|c|c|c|c|c|c|}
\hline Variables & $\begin{array}{c}\mathrm{CD} 4 \geq 350 n \\
(\%)\end{array}$ & $\begin{array}{c}\mathrm{CD} 4=200- \\
349 n(\%)\end{array}$ & $\begin{array}{c}\mathrm{CD} 4<200 n \\
(\%)\end{array}$ & OR & $95 \% \mathrm{CI}$ & p-value \\
\hline${ }^{*} G S T M 1(+)$ & $83(66.94)$ & $8(47.05)$ & $5(41.67)$ & 1.00 & & \\
\hline $\operatorname{GSTM1}(-)$ & $41(33.06)$ & $9(52.94)$ & $7(58.33)$ & 2.49 & $1.095-5.66$ & $0.033^{*}$ \\
\hline${ }^{*} G S T T 1(+)$ & $68(54.84)$ & $8(47.05)$ & $3(25.00)$ & 1.00 & & \\
\hline GSTT1(-) & $56(45.16)$ & $9(52.94)$ & $9(75.00)$ & 1.98 & $0.86-4.55$ & 0.147 \\
\hline${ }^{*} \operatorname{GSTM1}(+) / G S T T 1(+)$ & $49(39.52)$ & $4(23.53)$ & $1(8.33)$ & 1.00 & & \\
\hline $\operatorname{GSTM1}(-) / \operatorname{GSTT1}(+)$ & $19(15.32)$ & $4(23.53)$ & $2(16.67)$ & 3.09 & $0.84-11.35$ & 0.09 \\
\hline $\operatorname{GSTM1}(+) / \operatorname{GSTT1}(-)$ & $34(27.42)$ & $4(23.53)$ & $4(33.33)$ & 2.30 & $0.69-7.65$ & 0.23 \\
\hline $\operatorname{GSTM1}(-) / \operatorname{GSTT1}(-)$ & $22(17.74)$ & $5(29.41)$ & $5(41.67)$ & 4.45 & $1.36-14.57$ & $0.016^{*}$ \\
\hline
\end{tabular}

Analysis by chi-square to obtain odds ratio values (OR) and confidence interval; +: active; -: null; CD4+: Lymphocyte T CD4; CI: confidence interval; OR: odds ratio; ${ }^{*}$ : reference; *: significant difference between groups ( $\mathrm{p}<0.05$ ). The comparison was done between patients with CD4+ counts $\geq 350 \mathrm{cells} / \mathrm{mm}^{3}$ and 350 $<$ cells $/ \mathrm{mm}^{3}$.

The impact of GSTM1 and GSTT1 genes deletion on viral load of HIV-1 infected patient was show in Table 5. The baseline viral load level for failure or therapeutic success is 1000 copies/mL in accordance with WHO Consolidated Guidelines for the Use of Antiretroviral Drugs for the Treatment and Prevention of HIV Infections in 2016 [24]. Patients with viral load test results below the threshold should be considered as having suppressed viral loads but patients with viral load greater than 1000 copies $/ \mathrm{mL}$ after 12 months of treatment were defined as virological failures. A total of $57 \mathrm{HIV}-1$ patients had GSTM1-null, among them 48 had HIV-1 viral load $<1000$ copies/mL and 9 had HIV-1 viral load $\geq 1000$ copies $/ \mathrm{mL}$. Those with GSTT1-null were 74 and among them 66 had HIV-1 viral load $<1000$ copies $/ \mathrm{mL}$ and 8 had HIV-1 viral load $\geq 1000$ copies $/ \mathrm{mL}$. HIV-1 infected patients with the double genotype GSTM1-null/GSTT1-null were 32 and among them 25 and 7 had respectively HIV-1 viral load $<1000$ copies $/ \mathrm{mL}$ and $\geq 1000$ copies $/ \mathrm{mL}$. A statistically significant difference was found when we compared GSTM1 and GSTT1 variants frequencies in patients with HIV-1 viral load $<1000$ copies $/ \mathrm{mL}$ and those HIV-1 viral load $\geq 1000$ copies $/ \mathrm{mL}$. GSTM1-null genotype and the double genotype GSTM1-null/GSTT1-null variants were less frequent in patients with HIV-1 viral load $\geq 1000$ copies $/ \mathrm{mL}$, suggesting that GSTM1-null genotype $(\mathrm{OR}=5.81,95 \% \mathrm{CI}=1.50-22.74, \mathrm{p}=0.009)$ and the double genotype GSTM1-null/GSTT1-null (OR $=7.28,95 \% \mathrm{CI}=1.40-37.61, \mathrm{p}$ $=0.011)$ were associated with an higher risk to have HIV-1 viral load $\geq 1000$ copies/mL.

\section{Discussion}

From our knowledge, this study is the first to assess the association between GSTM1 and GSTT1 genes deletion with HIV-1 infection and disease progression in Burkinabe patients. 
Table 5. Impact of GSTM1 and GSTT1 deletion on HIV-1 patients' viral loads.

\begin{tabular}{|c|c|c|c|c|c|c|}
\hline Variables & $\begin{array}{c}\mathrm{VL}<1000 n \\
(\%)\end{array}$ & $\begin{array}{c}\mathrm{VL} \geq 1000 n \\
(\%)\end{array}$ & Total $n(\%)$ & OR & $95 \%$ CI & p-value \\
\hline${ }^{\#} G S T M 1(+)$ & $93(65.96)$ & $3(25.00)$ & $96(63.00)$ & 1.00 & & \\
\hline $\operatorname{GSTM1}(-)$ & $48(34.04)$ & $9(75.00)$ & $57(37.00)$ & 5.81 & $1.50-22.74$ & $0.009^{*}$ \\
\hline \#GSTT1(+) & $75(53.19)$ & $4(33.33)$ & $79(51.63)$ & 1.00 & & \\
\hline GSTT1(-) & $66(46.81)$ & $8(66.67)$ & $74(48.37)$ & 2.27 & $0.65-7.89$ & 0.23 \\
\hline${ }^{\#} \operatorname{GSTM1}(+) / G S T T 1(+)$ & $52(36.88)$ & $2(16.70)$ & $54(35.29)$ & 1.00 & & \\
\hline GSTM1(-)/GSTT1(+) & $23(16.31)$ & $2(16.70)$ & $25(16.34)$ & 2.26 & $0.29-17.05$ & 0.58 \\
\hline $\operatorname{GSTM1}(+) / \operatorname{GSTT1}(-)$ & $41(29.07)$ & $1(8.33)$ & $42(27.45)$ & 0.63 & $0.05-7.24$ & 1.00 \\
\hline $\operatorname{GSTM1}(-) / \operatorname{GSTT1}(-)$ & $25(17.73)$ & $7(58.33)$ & $32(20.91)$ & 7.28 & $1.40-37.61$ & $0.011^{*}$ \\
\hline
\end{tabular}

Analysis by chi-square to obtain odds ratio values (OR) and confidence interval; +: active; -: null; VL: HIV-1 Viral Load; CI: confidence interval; OR: odds ratio; *: reference; *: significant difference between groups $(\mathrm{p}<0.05)$.

In the general population study, women were more represented than men and among HIV-1 infected patients, they were more infected by HIV-1 than men (66.7\% versus $33.3 \%$ respectively) (Table 2 ). Due to the high proportion of women in HIV-1 infected patients, certain studies suggested that women had an increasing risk of being infected by HIV than men. According to World health Organization, Women are more likely to be infected with HIV in any type of sexual intercourse than men because of biological factors; the mucosal areas exposed during sexual intercourse are larger in women than in men [25]. Moreover some, countries as Burkina Faso, through the prevention of mother to child program of HIV infection, HIV test for all pregnant women is recommended. This could explain the high proportion of HIV-1 infected women. The proportions of HIV-1 infected patients aged $\geq 40$ years were high (81.70\%). Decreasing in HIV-related mortality since the introduction of combination antiretroviral therapy has resulted in increased life expectancy and an aging HIV-positive population [26]. Individuals aged $\geq 40$ years in the general study population were 9.82 times more likely to be infected by HIV-1 compared to individuals aged $\leq 39$ years (Table 2). HIV, HBV and HCV tests were performed in controlled subjects; HBV and HVC tests were performed in HIV positive patients to rule out possible cases of infection with these viruses.

In accordance with WHO Consolidated Guidelines for the Use of Antiretroviral Drugs for the Treatment and Prevention of HIV Infections in 2016 [24], $81.04 \%$ of patients $\left(\mathrm{CD} 4^{+} \geq 350\right.$ cells $/ \mathrm{mm}^{3}$ and viral load $<1000$ copies $\left./ \mathrm{mL}\right)$ should be considered as having suppressed viral load and $7.8 \%$ of patients $\left(\mathrm{CD}^{+}\right.$ $<200$ cells $/ \mathrm{mm}^{3}$ and viral load $\geq 1000$ copies $/ \mathrm{mL}$ ) were defined as virological failure. The therapeutic failure could be due to virus factors and/or host-genetic factors that could potentially modulate cellular susceptibility to HIV replication. Indeed, some studies in Burkina Faso have shown that host genetic factors could confer susceptibility or protection against HIV infection, Kagoné et al. (2014) in their study suggested a protective role of a variation of $D C$-SIGN promoter and 
genetic resistance to HIV-1 in serodiscordant couples, Compaore et al., (2016) demonstrate that some $A P O B E C 3 G$ variants were associated with HIV-1 infection [6] [7].

Glutathione S-transferase (GSTs) are a super family of drug metabolizing enzymes with a high level of conjugation specificity for glutathione (GSH) and the enzymes are essential for metabolism of many substances, responsible in part for response to oxidative stress in humans. GSTM1-null and GSTT1-null genotypes are deletion variants associated with the lack of a group of enzymes associated to the susceptibility of drug metabolizing and progression of certain diseases, such as infectious diseases, cancers and others.

Our study showed in the general study population that the frequency of GSTM1-null and GSTT1-null were $30.35 \%$ and $35.46 \%$ respectively (Table 3 ). There were several studies about GSTM1 and GSTT1 gene polymorphisms implication in some diseases, Piacentini et al., (2011) who showed that the distribution of genotypes varies among ethnic groups [27]. Palma-Cano et al., (2017) estimated that in worldwide frequencies of the GSTT1-null ranges from $10 \%$ to $51 \%$ and those of GSTM1-null genotypes from $11 \%$ to $67 \%$ [28]. In our study, GSTM1-null frequency (30.35\%) is comparable with those in African population such as Cameroon (28\%) [27], Tanzania (33\%) [29], higher than Zimbabwe (24\%) [29], but lower than those such as Ivory Coast (36\%) [30], Egypt (55\%) [31], Tunisia (46\%) [32], Morocco (45\%) [33]. Concerning the frequency of GSTT1-null genotype in our population (35.46\%), it is comparable with those in Gambian (37\%) [34], higher than Egypt (30\%) [31], Morocco (22\%) [33], but lower than Cameroon (47\%) [27], Somalia (44\%) [35] and Tunisia (44\%) [32].

In the present study we also analyzed the relationship between GSTM1 and GSTT1 variants and HIV-1 infection and disease progression in Burkina Faso. Association between GSTM1 and GSTT1 polymorphisms and HIV-1 disease progression has long been studied. Singh et al., (2017) showed that GSTT1-null and GSTM1-null genotypes alone and in combination may predict the acquisition of hepatotoxicity, so disease progression [36]. Ciccacci et al., (2017) shown that only GSTM1-null was associated to HIV disease progression [37]. Kuleape et al., (2018) found that double deletion of glutathione S-transferase M1 and T1 is statistically associated with normal CD4+ count in Ghanaians patients diagnosed with HIV/ AIDS [38]. Parsons et al., (2013) shown that the GSTM1 genotype coding for the functional antioxidant enzyme is associated with lower HIV disease severity and with lower oxidative stress, compared to GSTM1 null-allele polymorphism, HIV infected patients with GSTM1 genotype coding for the functional antioxidant enzyme had higher CD4 cell count, lower HIV viral load and ART reduced oxidative stress [39].

This study showed that the frequency of GSTM1-null, GSTT1-null, GSTM1active/GSTT1-null and the double genotype GSTM1-null/GSTT1-null were higher in HIV-1 infected patients group than controls group and differences were significant, indicating a possible association between GSTM1-null genotype, GSTT1-null and the double genotype GSTM1-null/GSTT1-null and risk of 
HIV-1 infection.

When we grouped the GST polymorphism according to CDC staging of CD4+ count (Table 4) and HIV-1 viral Load according to WHO Consolidated Guidelines for the Use of Antiretroviral Drugs for the Treatment and Prevention of HIV Infections in 2016 (Table 5), we found that GSTM1-null genotype and the double genotype GSTM1-null/GSTT1-null were associated with low $\mathrm{CD} 4^{+}$count $\left(<350\right.$ cells $\left./ \mathrm{mm}^{3}\right)$ and high HIV-1 viral load $(\geq 1000$ copies $/ \mathrm{mL})$. This indicate that GSTM1-null genotype and the double genotype GSTM1-null/GSTT1-null were deletion variants associated with the lack of enzymes activity and the susceptibility to antiretroviral drug metabolizing. Glutathione S-transferase (GSTs) play a role in the detoxification of the reactive oxygen species [40]. Several studies showed that GSTM1-null and GSTT1-null allele polymorphism is associated with reduced mitochondrial enzyme activity, decreased ability to detoxify compounds, increased level of reactive oxygen species, and increased risk of cancers [41] [42] [43]. Increased levels of oxidative stress in HIV infected patients, relative to healthy subjects, have been demonstrated [44] [45] [46]. The deletion of GSTM1 and both GSTM1/GSTT1 could favor accumulation of reactive oxygen species and increased the risk of HIV-1 disease progression by some difficulty to metabolize antiretroviral drug. Polymorphism in GST is associated to higher risk of oxidative stress, which has been suggested to favor HIV replication and disease progression [11] [12].

\section{Conclusion}

Our results suggest that GSTM1-null genotype, GSTT1-null genotype and the double genotype GSTM1-null/GSTT1-null were associated with HIV-1 disease progression in the Burkinabe population. The study showed also that GSTM1null genotype and the double genotype GSTM1-null/GSTT1-null were associated with low $\mathrm{CD}^{+} \mathrm{T}$ cells counts and high HIV-1 viral load in HIV-1 infected patients on ART. However, larger studies will be necessary to fully understand the role of GST variant in the HIV-1 disease progression.

\section{Authors' Contributions}

Study concept and design: PAS, FWD, ATY and JS.

Sampling and Laboratory analysis: FWD, PAS, STS, HKS, ITK, ATY and JS.

Statistical analysis and interpretation of data: FWD, PAS, STS, ATY, TRC and AKO.

Drafting of the manuscript: FWD, PAS, STS, ATY, BMN, TRC, HKS, ITK, AKO, BVJTEB and JS.

Critical revision of the manuscript for important intellectual content: FWD, ATY, BMN and JS.

Administrative, technical, and material support: BMN, ATY, FWD and JS.

Study supervision: FWD and JS.

Manuscript Approval: All authors have read and approved the manuscript. 


\section{Conflicts of Interest}

The authors declare no conflicts of interest regarding the publication of this paper.

\section{References}

[1] OMS (2017) VIH/sida aide memoire.

[2] ONUSIDA (2018) Dernières statistiques sur l'état de l'épidémie de sida. http://www.unaids.org/fr/resources/fact-sheet

[3] Brites, C., et al. (2016) Extensive Variation in Drug-Resistance Mutational Profile of Brazilian Patients Failing Antiretroviral Therapy in Five Large Brazilian Cities. The Brazilian Journal of Infectious Diseases, 20, 323-329. https://doi.org/10.1016/j.bjid.2016.03.010

[4] Ndahimana, J., et al. (2016) Drug Resistance Mutations after the First 12 Months on Antiretroviral Therapy and Determinants of Virological Failure in Rwanda. Tropical Medicine \& International Health, 21, 928-935. https://doi.org/10.1111/tmi.12717

[5] Zhou, Y., et al. (2016) Prevalence of HIV Antiretroviral Drug Resistance and Its Impacts on HIV-1 Virological Failures in Jiangsu, China: A Cross-Sectional Study. BioMed Research International, 2016, Article ID: 1752437. https://doi.org/10.1155/2016/1752437

[6] Compaore, T.R., et al. (2016) APOBEC3G Variants and Protection against HIV-1 Infection in Burkina Faso. PLoS ONE, 11, e0146386.

https://doi.org/10.1371/journal.pone.0146386

[7] Kagone, T.S., et al. (2014) A Variant of DC-SIGN Gene Promoter Associated with Resistance to HIV-1 in Serodiscordant Couples in Burkina Faso. Asian Pacific Journal of Tropical Medicine, 7, S93-S96. https://doi.org/10.1016/S1995-7645(14)60211-X

[8] Strange, R.C., Spiteri, M.A., Ramachandran, S. and Fryer, A.A. (2001) Glutathione$S$-Transferase Family of Enzymes. Mutation Research, 482, 21-26. https://doi.org/10.1016/S0027-5107(01)00206-8

[9] Board, P.G., et al. (2000) Identification, Characterization, and Crystal Structure of the Omega Class Glutathione Transferases. The Journal of Biological Chemistry, 275, 24798-24806. https://doi.org/10.1074/jbc.M001706200

[10] Mannervik, B. and Danielson, U.H. (1988) Glutathione Transferases-Structure and Catalytic Activity. Critical Reviews in Biochemistry, 23, 283-337. https://doi.org/10.3109/10409238809088226

[11] Watson, R.W., et al. (1997) Augmented Intracellular Glutathione Inhibits Fas-Triggered Apoptosis of Activated Human Neutrophils. Blood, 89, 4175-4181. https://doi.org/10.1182/blood.V89.11.4175

[12] Zhao, L., et al. (2000) Molecular Modeling and in Vitro Activity of an HIV-1-Encoded Glutathione Peroxidase. Proceedings of the National Academy of Sciences of the United States of America, 97, 6356-6361.https://doi.org/10.1073/pnas.97.12.6356

[13] DeMarini, D.M., et al. (1997) Glutathione S-Transferase-Mediated Induction of GC $\rightarrow$ AT Transitions by Halomethanes in Salmonella. Environmental and Molecular Mutagenesis, 30, 440-447. https://doi.org/10.1002/(SICI)1098-2280(1997)30:4<440::AID-EM9>3.0.CO;2-M

[14] Pemble, S., et al. (1994) Human Glutathione S-Transferase Theta (GSTT1): cDNA 
Cloning and the Characterization of a Genetic Polymorphism. Biochemical Journal, 300, 271-276. https://doi.org/10.1042/bj3000271

[15] Soto-Quintana, O., et al. (2015) Association of the GSTM1 Null Polymorphism with Breast Cancer in a Mexican Population. Genetics and Molecular Research, 14, 13066 13075. https://doi.org/10.4238/2015.October.26.2

[16] Khabaz, M.N., et al. (2016) GSTM1 Gene Polymorphism and the Risk of Colorectal Cancer in a Saudi Arabian Population. Genetics and Molecular Research, 15, 1-9. https://doi.org/10.4238/gmr.15017551

[17] Kirk, G.D., et al. (2005) Hepatocellular Carcinoma and Polymorphisms in Carcinogen-Metabolizing and DNA Repair Enzymes in a Population with Aflatoxin Exposure and Hepatitis B Virus Endemicity. Cancer Epidemiology, Biomarkers \& Prevention, 14, 373-379. https://doi.org/10.1158/1055-9965.EPI-04-0161

[18] Lu, L., et al. (2014) Association of Glutathione $S$-Transferase M1/T1 Polymorphisms with Susceptibility to Vitiligo. Gene, 535, 12-16. https://doi.org/10.1016/j.gene.2013.11.024

[19] Nomani, H., et al. (2011) The Association between GSTT1, M1, and P1 Polymorphisms with Coronary Artery Disease in Western Iran. Molecular and Cellular Biochemistry, 354, 181-187. https://doi.org/10.1007/s11010-011-0817-2

[20] Sui, Y., et al. (2011) Association of Glutathione S-Transferase M1 and T1 Null Polymorphisms with the Development of Cervical Lesions: A Meta-Analysis. European Journal of Obstetrics and Gynecology, 159, 443-448. https://doi.org/10.1016/j.ejogrb.2011.09.012

[21] Miller, S.A., Dykes, D.D. and Polesky, H.F. (1988) A Simple Salting out Procedure for Extracting DNA from Human Nucleated Cells. Nucleic Acids Research, 16, 1215. https://doi.org/10.1093/nar/16.3.1215

[22] Chen, C.L., et al. (1997) Higher Frequency of Glutathione S-Transferase Deletions in Black Children with Acute Lymphoblastic Leukemia. Blood, 89, 1701-1707. https://doi.org/10.1182/blood.V89.5.1701

[23] CDC (2013) Diagnoses of HIV Infection in the United States and Dependent Areas. HIV Surveillance Report, Volume 23.

[24] WHO (2016) Consolidated Guidelines on the Use of Antitrtroviral Drugs for Treating and Preventing HIV Infection Recommendations for a Public Health Approach. https://www.who.int/hiv/pub/arv/summary-recommendations.pdf

[25] WHO (2019) Inégalités entre les sexes et VIH/sida. https://www.who.int/gender/hiv aids/fr/

[26] Deeks, S.G. and Phillips, A.N. (2009) HIV Infection, Antiretroviral Treatment, Ageing, and Non-AIDS Related Morbidity. BMJ, 338, a3172. https://doi.org/10.1136/bmj.a3172

[27] Piacentini, S., et al. (2011) GSTT1 and GSTM1 Gene Polymorphisms in European and African Populations. Molecular Biology Reports, 38, 1225-1230. https://doi.org/10.1007/s11033-010-0221-0

[28] Palma-Cano, L.E., et al. (2017) GSTT1 and GSTM1 Null Variants in Mestizo and Amerindian Populations from Northwestern Mexico and a Literature Review. Genetics and Molecular Biology, 40, 727-735. https://doi.org/10.1590/1678-4685-gmb-2016-0142

[29] Dandara, C., et al. (2002) Genetic Polymorphism of Cytochrome P450 1A1 (Cyp1A1) and Glutathione Transferases (M1, T1 and P1) among Africans. Clinical Chemistry and Laboratory Medicine, 40, 952-957. 
https://doi.org/10.1515/CCLM.2002.167

[30] Santovito, A., Burgarello, C., Cervella, P. and Delpero, M. (2010) Polymorphisms of Cytochrome P450 1A1, Glutathione s-Transferases M1 and T1 Genes in Ouangolodougou (Northern Ivory Coast). Genetics and Molecular Biology, 33, 434-437. https://doi.org/10.1590/S1415-47572010005000059

[31] Hamdy, S.I., et al. (2003) Genotype and Allele Frequencies of TPMT, NAT2, GST, SULT1A1 and MDR-1 in the Egyptian Population. British Journal of Clinical Pharmacology, 55, 560-569. https://doi.org/10.1046/j.1365-2125.2003.01786.x

[32] Ouerhani, S., et al. (2006) The Role of Glutathione Transferases M1 and T1 in Individual Susceptibility to Bladder Cancer in a Tunisian Population. Annals of Human Biology, 33, 529-535. https://doi.org/10.1080/03014460600907517

[33] Kassogue, Y., et al. (2014) Effect of Interaction of Glutathione S-Transferases (T1 and M1) on the Hematologic and Cytogenetic Responses in Chronic Myeloid Leukemia Patients Treated with Imatinib. Medical Oncology, 31, 47. https://doi.org/10.1007/s12032-014-0047-Z

[34] Wild, C.P., et al. (2000) Environmental and Genetic Determinants of Aflatoxin-Albumin Adducts in the Gambia. International Journal of Cancer, 86, 1-7. https://doi.org/10.1002/(SICI)1097-0215(20000401)86:1<1::AID-IJC1>3.0.CO;2-I

[35] Buchard, A., Sanchez, J.J., Dalhoff, K. and Morling, N. (2007) Multiplex PCR Detection of GSTM1, GSTT1, and GSTP1 Gene Variants: Simultaneously Detecting GSTM1 and GSTT1 Gene Copy Number and the Allelic Status of the GSTP1 Ile105Val Genetic Variant. The Journal of Molecular Diagnostics, 9, 612-617.

https://doi.org/10.2353/jmoldx.2007.070030

[36] Singh, H.O., et al. (2017) Impact of GSTM1, GSTT1 and GSTP1 Gene Polymorphism and Risk of ARV-Associated Hepatotoxicity in HIV-Infected Individuals and Its Modulation. The Pharmacogenomics Journal, 17, 53-60. https://doi.org/10.1038/tpj.2015.88

[37] Ciccacci, C., et al. (2017) Impact of Glutathione Transferases Genes Polymorphisms in Nevirapine Adverse Reactions: A Possible Role for GSTM1 in SJS/TEN Susceptibility. European Journal of Clinical Pharmacology, 73, 1253-1259. https://doi.org/10.1007/s00228-017-2295-2

[38] Kuleape, J.A., Tagoe, E.A., Puplampu, P., Bonney, E.Y. and Quaye, O. (2018) Homozygous Deletion of Both GSTM1 and GSTT1 Genes Is Associated with Higher CD4+ T Cell Counts in Ghanaian HIV Patients. PLoS ONE, 13, e0195954. https://doi.org/10.1371/journal.pone.0195954

[39] Parsons, M., et al. (2013) Effect of GSTM1-Polymorphism on Disease Progression and Oxidative Stress in HIV Infection: Modulation by HIV/HCV Co-Infection and Alcohol Consumption. Journal of AIDS and Clinical Research, 4, Article ID: 10002337.

[40] Ketterer, B. (2001) A Bird's Eye View of the Glutathione Transferase Field. Chemico-Biological Interactions, 138, 27-42. https://doi.org/10.1016/S0009-2797(01)00277-0

[41] Economopoulos, K.P. and Sergentanis, T.N. (2010) GSTM1, GSTT1, GSTP1, GSTA1 and Colorectal Cancer Risk: A Comprehensive Meta-Analysis. European Journal of Cancer, 46, 1617-1631. https://doi.org/10.1016/j.ejca.2010.02.009

[42] Liu, D., Liu, Y., Ran, L.M., Shang, H.P. and Li, D.T. (2013) GSTT1 and GSTM1 Polymorphisms and Prostate Cancer Risk in Asians: A Systematic Review and Meta-Analysis. Tumor Biology, 34, 2539-2544. https://doi.org/10.1007/s13277-013-0778-Z

[43] Wang, D., Wang, B., Zhai, J.X., Liu, D.W. and Sun, G.G. (2011) Glutathione 
S-Transferase M1 and T1 Polymorphisms and Cervical Cancer Risk: A Meta-Analysis. Neoplasma, 58, 352-359. https://doi.org/10.4149/neo 201104352

[44] Gil, L., et al. (2003) Contribution to Characterization of Oxidative Stress in HIV/AIDS Patients. Pharmacological Research, 47, 217-224.

https://doi.org/10.1016/S1043-6618(02)00320-1

[45] Morris, D., et al. (2012) Unveiling the Mechanisms for Decreased Glutathione in Individuals with HIV Infection. Clinical and Developmental Immunology, 2012, Article ID: 734125. https://doi.org/10.1155/2012/734125

[46] Repetto, M., et al. (1996) Oxidative Stress in Blood of HIV Infected Patients. Clinica Chimica Acta, 255, 107-117. https://doi.org/10.1016/0009-8981(96)06394-2 